\title{
Dementia prevention: current epidemiological evidence and future perspective
}

\author{
Francesca Mangialasche*1,2, Miia Kivipelto, ${ }^{1,3}$, Alina Solomon ${ }^{1,3}$ and Laura Fratiglioni'
}

\begin{abstract}
Dementia, a major cause of disability and institutionalization in older people, poses a serious threat to public health and to the social and economic development of modern society. Alzheimer's disease (AD) and cerebrovascular diseases are the main causes of dementia; most dementia cases are attributable to both vascular and neurodegenerative brain damage. No curative treatment is available, but epidemiological research provides a substantial amount of evidence of modifiable risk and protective factors that can be addressed to prevent or delay onset of $\mathrm{AD}$ and dementia. Risk of late-life dementia is determined by exposures to multiple factors experienced over the life course, and the effect of specific risk/protective factors depends largely on age. Moreover, cumulative and combined exposure to different risk/protective factors can modify their effect on dementia/AD risk. Multidisciplinary research involving epidemiology, neuropathology, and neuroimaging has provided sufficient evidence that vascular risk factors significantly contribute to the expression and progression of cognitive decline (including dementia) but that active engagement in social, physical, and mentally stimulating activities may delay the onset of dementia. However, these findings need to be confirmed by randomized controlled trials (RCTs). A promising strategy for preventing dementia is to implement intervention programs that take into account both the life-course model and the multifactorial nature of this syndrome. In Europe, there are three ongoing multidomain interventional RCTs that focus on the optimal management of vascular risk factors and vascular diseases. The RCTs include medical and lifestyle interventions and promote social, mental, and physical activities aimed at increasing the cognitive reserve. These studies will provide new insights into prevention of cognitive impairment and dementia. Such knowledge can help researchers plan larger, international prevention trials that could provide robust evidence on dementia/AD prevention. Taking a step in this direction, researchers involved in these European RCTs recently started the European Dementia Prevention Initiative, an international collaboration aiming to improve strategies for preventing dementia.
\end{abstract}

\section{Introduction}

Dementia is an acquired disabling syndrome characterized by progressive deterioration in multiple cognitive domains and is severe enough to interfere with daily functioning. Alzheimer's disease (AD) is the most common cause of dementia, but increasing evidence from population-based neuropathological and neuroimaging studies shows that mixed brain pathologies (neurodegenerative and vascular) account for most dementia cases, especially in very old people $[1,2]$.

Both prevalence and incidence of dementia rise exponentially with advancing age, and $70 \%$ of all dementia

*Correspondence: francesca.mangialasche@ki.se

'Aging Research Center, Department of Neurobiology, Care Sciences and Society (NVS), Karolinska Institutet (KI)-Stockholm University, Gävlegatan 16 (9th floor)

SE-113 30, Stockholm, Sweden

Full list of author information is available at the end of the article cases occur in people who are at least 75 years old [3]. The worldwide increase in the number of older adults, more pronounced in those who are at least 80 years old, explains the epidemic proportions assumed by dementia. Because dementia is a major cause of disability in and institutionalization of older people, the increased prevalence of this syndrome places enormous pressures on health-care systems and society. The World Alzheimer Report estimates that, in 2010, the number of people with dementia worldwide was 35.6 million and that this will increase to 65.7 million by 2030 and 115.4 million by 2050 unless effective means of reducing the incidence of this disease are introduced [4]. In 2010, the total estimated worldwide costs of dementia were USD \$604 billion, including the costs of informal care (unpaid care provided by family and others), direct costs of social care (provided by community care professionals and in residential home settings), and the direct costs of medical care (the costs of treating 
dementia and other conditions in primary and secondary care) [4].

No curative treatment is available, but epidemiological research provides substantial evidence of modifiable risk and protective factors that can be addressed to prevent or delay AD and dementia onset. In this review, we summarize the evidence supporting dementia/AD prevention and discuss key aspects that need to be considered when planning preventive strategies.

\section{Prevention of dementia: current evidence from observational studies}

Over the last decades, the etiology of dementia has been extensively studied with the aim of identifying efficacious prevention and treatment strategies. These efforts have led to the broad consensus that dementia is a multifactorial disorder caused by several interrelated mechanisms in which the interaction of genetic and environmental factors plays the major role (Table 1).

The pathways that lead from different risk factors to dementia are not fully understood, but several etiological hypotheses have been proposed: the vascular hypothesis, inflammatory hypothesis, oxidative stress hypothesis, toxic hypothesis, and psychosocial hypothesis [5,6]. These theories highlight potential links of various risk factors to both the vascular and the neurodegenerative brain pathologies that can cause dementia, justifying the validity of dementia syndrome as target for prevention $[7,8]$.

A recent report commissioned by the National Institutes of Health (NIH) and issued by the Agency for Healthcare Research and Quality (AHRQ) concluded that current research evidence on many risk and protective factors for cognitive decline and $\mathrm{AD}$ is not of sufficient strength, thus recommendations for preventing these conditions cannot be made $[9,10]$. Another previous review yielded similar conclusions [11]. These negative perspectives have been criticized since epidemiological evidence that the use of antihypertensive medications, cessation of smoking, and increasing physical activity produce cognitive benefits in older adults is not inadequate [12], and the analytical strategy used in the evidence-based review did not take into account the life-course perspective [13]. In fact, observational longitudinal studies clearly show that the risk of late-life dementia is determined by exposures to multiple factors experienced over the life span and that the effect of specific risk/protective factors depends largely on age. Thus, a life-course perspective is relevant for chronic disorders (such as dementia) that have a long latent period. It allows the identification of time windows when exposures have their greatest effect on outcome and assessment of whether cumulative exposures could have multiplicative or additive effects over the life course [6].
Age-dependent associations with dementia/AD have been suggested for several aging-related medical conditions. For example, elevated blood pressure, body mass index (BMI), and total cholesterol levels at a young age and in middle age ( $<65$ years) are associated with an increased risk of dementia and $\mathrm{AD}$, and having lower values in late life ( $>75$ years) is also associated with subsequent development of dementia/AD [14-19]. Diabetes mellitus has been associated with increased risk of dementia and $\mathrm{AD}$ over adult life, but the risk is stronger when diabetes occurs in mid-life than in late-life [20]. Current smoking is another major risk factor for dementia and $\mathrm{AD}$, and, given the worldwide prevalence of smoking, about $14 \%$ of all AD cases are potentially attributable to this risk factor [21]. Although it is not entirely clear whether depression is a risk factor for or a preclinical symptom of dementia, studies with long-term follow-up support the risk factor hypothesis [22].

Protective factors for dementia and AD have also been identified; these include high education and socioeconomic status in early life as well as a number of factors in adult life: high work complexity, rich social network, social engagement, mentally stimulating activity, nonsmoking, and regular physical exercise [5,23,24]. Living with a partner during mid-life has been associated with reduced risk of cognitive impairment and dementia later in life, suggesting that being in a relationship entails cognitive and social challenges that can increase the cognitive reserve [25]. Even at old ages, the active engagement in mental, physical, and social activities may postpone the onset of dementia, possibly by increasing the cognitive reserve [26].

In addition, several follow-up studies reported a decreased dementia risk associated with healthy dietary patterns and nutritional factors, such as high adherence to a Mediterranean diet or dietary intake of antioxidants (for example, vitamins $\mathrm{E}$ and $\mathrm{C}$ ) and $\omega-3$ polyunsaturated fatty acid (PUFA) (often measured as fish consumption) [27-31].

Cumulative and combined exposure to different risk factors can lead to modified effects on dementia/AD risk (Table 1). In the Finnish CAIDE (Cardiovascular Risk Factors, Aging and Incidence of Dementia) study, the risk of dementia has been evaluated in relation to a score (CAIDE Dementia Risk Score) combining mid-life risk factors, including low education and cardiovascular factors (that is, hypertension, obesity, hypercholesterolemia, and physical inactivity). The risk of dementia increased as the score increased in a dose-response trend, making it possible to identify individuals who can greatly benefit from preventive intervention that targets vascular risk factors [32]. Similar findings have been reported for late-life exposures: in the Swedish Kungsholmen Project, the cumulative effect of vascular risk factors 
Table 1. Risk and protective factors for dementia and Alzheimer's disease

\begin{tabular}{|c|c|c|}
\hline Risk factors & Protective factors & Combined effects \\
\hline \multirow{3}{*}{$\begin{array}{l}\text { Genetic } \\
\text { ApoE } \varepsilon 4 \\
\text { Familial aggregation }\end{array}$} & Psychosocial factors & Increased \\
\hline & High education and & 1. Genetic and environmental factors in mid-life \\
\hline & $\begin{array}{l}\text { socioeconomic status } \\
\text { High work complexity }\end{array}$ & $\begin{array}{l}\text { ApoE } \varepsilon 4 \text { magnifies the effect of high alcohol intake, smoking, physical } \\
\text { inactivity, and high intake of saturated fat. }\end{array}$ \\
\hline \multirow{4}{*}{$\begin{array}{l}\text { Vascular } \\
\text { Cerebrovascular lesions } \\
\text { Cardiovascular diseases } \\
\text { Diabetes mellitus and } \\
\text { prediabetes }\end{array}$} & Rich social network and social & 2. Vascular factors in mid-life \\
\hline & $\begin{array}{l}\text { engagement } \\
\text { Mentally stimulating activity }\end{array}$ & $\begin{array}{l}\text { Hypertension, obesity, hypercholesterolemia, and physical inactivity have } \\
\text { an additive effect when they co-occur. }\end{array}$ \\
\hline & & 3. Vascular factors/diseases in late life \\
\hline & $\begin{array}{l}\text { Lifestyle } \\
\text { Physical activity }\end{array}$ & $\begin{array}{l}\text { Higher risk in individuals with brain hypoperfusion profile: chronic heart } \\
\text { failure, low pulse pressure, and low diastolic pressure }\end{array}$ \\
\hline \multirow{2}{*}{$\begin{array}{l}\text { Positive association in mid-life but } \\
\text { negative association in late life }\end{array}$} & & $\begin{array}{l}\text { Higher risk in individuals with atherosclerosis profile: high systolic pressure, } \\
\text { diabetes mellitus or prediabetes, and stroke }\end{array}$ \\
\hline & Diet & Decreased \\
\hline Hypertenston & Meaiterranean diet & 1. Genetic and environmental factors in mid-life \\
\hline $\begin{array}{l}\text { High BMI (excessive weight and } \\
\text { obesity) }\end{array}$ & $\begin{array}{l}\text { Polyunsaturated and fish-related } \\
\text { fats }\end{array}$ & High education reduces the negative effect of ApoE $\varepsilon 4$. \\
\hline \multirow[t]{2}{*}{ High serum cholesterol } & Vitamins $B_{6}$ and $B_{12}$ and folate & Physical activity counteracts the risk due to $A p o E \varepsilon 4$. \\
\hline & Antioxidant vitamins (C and $\mathrm{E})$ & 2. Environmental factors in mid-life \\
\hline \multicolumn{2}{|l|}{ Lifestyle } & $\begin{array}{l}\text { High work complexity modulates the increased dementia risk due to low } \\
\text { education }\end{array}$ \\
\hline \multicolumn{2}{|l|}{ Smoking } & \\
\hline \multicolumn{3}{|l|}{ High alcohol intake } \\
\hline \multicolumn{3}{|l|}{ Diet } \\
\hline \multicolumn{3}{|l|}{ Saturated fats } \\
\hline \multicolumn{3}{|l|}{ Homocysteine } \\
\hline \multicolumn{3}{|l|}{ Others } \\
\hline Depression & & \\
\hline
\end{tabular}

and vascular diseases on dementia/AD risk has been investigated in people who are at least 75 years old. These factors were aggregated according to two pathophysiological hypotheses: the brain hypoperfusion profile, defined by chronic heart failure, low pulse pressure, and low diastolic pressure, and the atherosclerosis profile, which included high systolic pressure, diabetes mellitus or prediabetes, and stroke. In both profiles, dementia/AD risk increased with increasing scores in a dose-response manner, suggesting a synergy of vascular risk factors in promoting dementia/AD also in advanced age [33]. The American Cardiovascular Health Cognition Study developed a Late-life Dementia Risk Index and also a brief version, which groups older adults in the three categories of low, moderate, and high risk of developing dementia. Both versions of the index support the cumulative effect of different factors in determining the risk of dementia after the age of 65 years. These indices include information from different domains, including demographic factors (age), genetics (presence of the apolipoprotein E (ApoE) $\varepsilon 4$ allele), lifestyle (BMI of less than 18.5 and lack of alcohol consumption), comorbid vascular conditions (internal carotid artery thickening, angina, coronary artery bypass surgery, stroke, and peripheral artery disease), evidence of brain abnormalities shown by magnetic resonance imaging (white matter diseases or enlarged ventricles), cognitive test scores, and physical performances $[34,35]$.

The combined effect of genetic-environmental or environmental-environmental joint exposures may also lead to the attenuation of the dementia risk. Populationbased studies suggest an effect modification for the ApoE $\varepsilon 4$ allele, the most important genetic risk factor for sporadic $\mathrm{AD}$. ApoE $\varepsilon 4$ carriers seem more vulnerable to risk factors like alcohol drinking, smoking, physical inactivity, and high intake of saturated fat, indicating that people with genetic susceptibility may reduce their initial $\mathrm{AD}$ risk by lifestyle interventions (that is, physical activity, sufficient intake of PUFA, and avoiding excess alcohol drinking and smoking) [36]. Furthermore, it has been shown that high education may reduce dementia risk among ApoE $\varepsilon 4$ allele carriers [37]. In regard to the interactions among modifiable risk factors, results from the Kungsholmen Project suggested that complexity of work with data and people was related to a decreased dementia risk and that the highest level of work 
complexity may modulate the increased dementia risk due to low education [23].

In conclusion, even though for some risk and protective factors the role in dementia and AD needs to be clarified, evidence from observational studies points at different modifiable factors that can be managed in order to prevent or delay dementia onset. Moreover, epidemiological findings strongly suggest that the life-course approach model and the multifactorial nature of dementia and $\mathrm{AD}$ should be considered when planning any preventive strategy.

\section{Prevention of dementia: current evidence from interventional studies}

Interventional studies on dementia and $\mathrm{AD}$ prevention have tested different medications, including statins, antihypertensive drugs, estrogens alone or in combination with progestin (hormone replacement therapy, or HRT), non-steroidal anti-inflammatory drugs (NSAIDs), and nutraceuticals (folate, Ginkgo biloba, and vitamins $B_{12}, C$, and E). For all of these compounds, the protective effects suggested by observational studies have not been confirmed in randomized controlled trials (RCTs), the results of which are inconsistent or even suggest a detrimental effect on cognition (for example, NSAIDs and HRT) [38-41]. Few interventional studies implementing non-pharmacological approaches have been carried out. Among them, some RCTs on cognitive training and physical activity provided encouraging results, which need confirmation [38,42]. It is possible that the negative results from the RCTs done so far reflect the real inefficacy of the tested strategies in preventing dementia and $\mathrm{AD}$. However, the apparent contradiction of results from observational and interventional studies could be explained by several factors:

1. The intervention was done outside the time window during which management of a risk factor would reduce dementia risk: several risk factors exert their effect mainly during mid-life, whereas RCTs have been done in older adults. This is the case for vascular risk factors, which seem to be more relevant when the exposure occurs during mid-life. Moreover, the HRT research suggests that estrogens may have beneficial, neutral, or detrimental effects on the brain depending on age at treatment, type of menopause (natural versus medically or surgically induced), or stage of menopause [43]. This concept, called the "window of opportunity hypothesis', is in agreement with the life-course approach model. There is evidence of neuroprotective effects of estrogens in women before the age of natural menopause and in the early postmenopausal stage (50 to 60 years), whereas estrogens initiated in late postmenopause (65 to 79 years) increase the risk of cognitive impairment and dementia $[43,44]$. Two RCTs are ongoing and both are due to be completed this year; one is testing the effect of HRT in early postmenopause (Kronos Early Estrogen Prevention Study, or KEEPS; ClinicalTrials.gov identifier NCT00623311) and the other is comparing the effects of HRT in early and late postmenopause (Early Versus Late Intervention Trial With Estradiol, or ELITE; ClinicalTrials.gov identifier NCT00114517).

2. Short treatment and follow-up: many studies were of relatively short length. Thus, interventions have been implemented for a period that is not long enough to determine a neuroprotective effect, and the limited follow-up duration of many RCTs would not allow detection of differences in dementia incidence.

3. The statistical power was inadequate since some RCTs had small samples and dementia has been considered a secondary endpoint in most clinical trials (for example, antihypertensive therapy).

4. The choice of compounds tested in RCTs using nutraceuticals was not optimal: although several products have been tested, supplement composition is still a debated issue. For instance, whereas observational studies suggested that a balanced intake of different forms of vitamin $\mathrm{E}$ can be important for reducing dementia/AD risk, only one form ( $\alpha$-tocopherol) has been tested in RCTs, and the findings were conflicting $[29,30,45,46]$. Moreover, intake of high doses of $\alpha$ tocopherol supplements has been associated with increased hemorrhagic stroke and mortality risk [47].

5. Despite the multifactorial nature of dementia and the importance of combined risk exposures, most studies were based on a mono-intervention approach, almost always testing single agents or lifestyle interventions. In multifactorial conditions, a small reduction in multiple risk factors can substantially decrease overall risk.

In summary, despite the discrepancies between findings of observational and interventional studies and the disappointing results of intervention studies on dementia and $\mathrm{AD}$, methodological issues of the RCTs carried out thus far suggest that a valid evaluation of the efficacy of preventive measures has yet to be undertaken.

\section{Prevention of dementia: ongoing multidomain intervention studies}

The knowledge derived from the previously described observational and interventional studies paved the way for some ongoing RCTs on the prevention of cognitive decline and dementia. In Europe, there are three large ongoing RCTs: the Finnish Geriatric Intervention Study to Prevent Cognitive Impairment and Disability (FINGER), the Multidomain Alzheimer Preventive Trial (MAPT), and the Prevention of Dementia by Intensive Vascular Care (PreDIVA) study $[48,49]$. The common denominator 
of these studies is the multidomain approach, which aims to simultaneously target several risk factors for dementia in older adults, mainly by promoting lifestyle changes and adherence to medical treatments for vascular risk factors and vascular diseases. All RCTs exclude individuals with dementia and use clinical evaluation and neuropsychological tests to detect cognitive changes and dementia incidence as main outcomes. Furthermore, secondary outcomes include functional status, mood disorders, quality of life, adherence to the intervention programs, and utilization of health resources. The latter two aspects are essential from a public health perspective since they provide information on feasibility and costeffectiveness of prevention strategies. Additionally, both FINGER and MAPT include ancillary studies on neuroimaging (morphological and functional), cerebrospinal fluid, and blood markers related to AD pathophysiology in order to investigate the effect of the interventions on brain morphology and metabolism, clarify mechanisms underlying preventive measures, and identify biomarkers that can be used to monitor effects of interventions.

FINGER (ClinicalTrials.gov identifier NCT01041989) is a multicenter RCT aiming to prevent cognitive impairment, dementia, and disability in 60- to 77-year-olds. The study population is represented by 1,200 individuals who are at increased risk of dementia and who were selected according to the CAIDE Dementia Risk Score and the CERAD neuropsychological test battery [32,48]. The 2-year multidomain intervention includes nutritional guidance, physical activity, cognitive training, increased social activity, and intensive monitoring and management of metabolic and vascular risk factors (hypertension, dyslipidemia, obesity, and impaired glucose tolerance). Individuals in the reference group are given general public health advice on lifestyle and vascular risk factors. FINGER participants are recruited from previous population-based observational surveys (that is, FINRISK and FIN-D2D) with detailed retrospective information on lifestyle and vascular factors [48]. Thus, differences in these variables can be taken into account and this is normally not possible in RCTs. The primary outcome is cognitive decline measured by a sensitive Neuropsychological Test Battery and the Stroop and Trail-making tests, which can depict early cognitive impairment typical for $\mathrm{AD}$ and vascular dementia (VaD). The planned 7-year extended follow-up will allow detection of differences in dementia/AD incidence.

MAPT (ClinicalTrials.gov identifier NCT00672685) is a French multicenter RCT evaluating the efficacy of isolated supplementation with $\omega-3$ fatty acid, isolated multidomain intervention, or their combination in the prevention of cognitive decline in frail individuals who are at least 70 years old. One thousand six hundred eighty community-dwelling participants have been enrolled by using a frailty definition that includes three components: presence of memory complaints, limitation in one instrumental activity of daily living, and slow walking speed. The 3-year multidomain intervention consists of group training sessions (physical exercise, cognitive training, and nutritional advice) and yearly personalized preventive consultations that aim to identify dementia and frailty risk factors (vascular risk factors, nutritional problems, sensory deficits, mood disorders, and walking difficulties) and promote their management in collaboration with the general practitioner. Follow-up is 5 years, and the main outcome measure is the 3 -year change in cognitive function assessed with a neuropsychological test (Grober and Buschke) [48,50].

The PreDIVA study (Controlled-Trials.com identifier ISRCTN29711771) is a Dutch multicenter, open, cluster RCT comparing standard and intensive care of cardiovascular risk factors in preventing dementia and disability in older people. The study includes 3,534 communitydwellers who are 70 to 78 years old and who were recruited from primary care practices. The standard care is based on guidelines for Dutch general practice, whereas the multicomponent intensive vascular care addresses hypertension, hypercholesterolemia, smoking habits, excessive weight, physical inactivity, and diabetes mellitus, which are strictly controlled with medication and lifestyle interventions. Study duration is 6 years, and primary outcomes are incident dementia assessed according to standard criteria and disability as measured with the Academic Medical Center Linear Disability Scale [49].

Researchers involved in these large European trials (FINGER, MAPT, and PreDIVA) recently started the European Dementia Prevention Initiative (EDPI), an international collaboration to improve preventive strategies against dementia [51]. Collaboration and data sharing within the EDPI will allow refining of methodological aspects of prevention trials, including identification of target populations, improvement of intervention methods (that is, type, intensity, and duration), and development and standardization of relevant outcome measures and prognostic and monitoring tools that can be easily implemented in large populations. This will help planning larger, international prevention trials able to provide robust evidence on dementia/AD prevention.

\section{Conclusions}

Although the pathogenesis of dementia is not fully elucidated, primary prevention seems possible as most factors involved in dementia onset and progression are modifiable or amenable to management. The recent AHRQ/NIH report shows that development of successful preventive strategies requires a more refined knowledge of risk and protective factors for dementia and AD as well as a validation of the observational studies with large 
intervention studies [7]. AD and $\mathrm{VaD}$ share several risk factors, and most dementia cases are attributable to both vascular and neurodegenerative brain damage. Furthermore, population-based neuropathological studies have shown that both subclinical neurodegenerative (amyloid plaques, neurofibrillary tangles, and Lewy bodies) and vascular lesions (and their co-occurrence) are common in the brains of cognitively normal older individuals [52]. In light of this, preventive strategies aiming to postpone the onset of dementia syndrome have great potential.

Epidemiological research suggests that the most effective strategy may be to encourage the implementation of multiple preventive measures throughout the life course, including high educational attainment in childhood and early adulthood, active control of vascular factors and disorders over adulthood, and maintenance of mentally, physically, and socially active lifestyles during middle age and later in life. It has been estimated that half of $\mathrm{AD}$ cases worldwide are potentially attributable to modifiable risk factors, and a $10 \%$ to $25 \%$ reduction in these factors could potentially prevent 3 million AD cases worldwide, and a reduction in all risk factors would have the greatest impact on dementia prevalence [21]. However, RCTs are indispensable to confirm the effect of risk reduction strategies targeting multiple risk factors. Multidomain interventional RCTs are ongoing and will provide new insights into prevention of cognitive impairment and dementia. Full implementation of the lifecourse approach is more challenging because of the difficulties of carrying out RCTs over many decades. Such long-term studies would require very large sample sizes and huge financial resources, and a pragmatic way to assess the effect of long-term interventions within an $\mathrm{RCT}$ has not yet been established. Furthermore, for ethical reasons, several risk and protective factors are not appropriate for intervention trials. Thus, evidence about these factors relies on conducting rigorous observational studies (for example, placebo-controlled trials for high blood pressure or cholesterol are not possible, because such treatments are known to protect against cardiovascular/cerebrovascular diseases) [9]. Methodological alternatives to RCTs have been proposed to obtain robust evidence on $\mathrm{AD}$ and dementia prevention [11,53]. The ongoing RTCs on dementia prevention will have to take into account the 'window of opportunity hypothesis' when evaluating the results of interventions. In fact, efficacy of preventive actions may vary by age. Thus, implementation of interventions at the appropriate time in the life course is crucial for successful prevention. Refining of prognostic tools, which can be used for early detection of subjects at risk of dementia in the general population, will also help to better plan intervention studies. Also, when older individuals are targeted, the frequent coexistence of chronic diseases needs to be considered since it can negatively impact cognitive performance and limit adherence to preventive interventions. On the other hand, appropriate management of morbidity can help improve cognitive performance and delay dementia onset. For instance, although stroke is a known risk factor for dementia, it has been recently reported that about $25 \%$ of stroke patients discontinued one or more of their prescribed secondary prevention medications within 3 months of hospitalization for acute stroke [54-56]. Improving long-term adherence to poststroke treatment can prevent recurrent cerebrovascular diseases and contribute to preventing or delaying clinical expression of dementia syndrome. Additionally, there is evidence of inadequate management of hypertension and hypercholesterolemia in older adults [49]. Similar situations exist for heart failure, which increases the risk of dementia among older adults [56], and diabetes mellitus, which accelerates the progression from mild cognitive impairment to dementia by more than 3 years [57]. Preliminary results from the PreDIVA study showed that $87 \%$ of the study participants have at least one modifiable risk factor amenable to intervention, proving the presence of a window of opportunity for improved risk management [49].

In conclusion, prevention of dementia is now moving from observational to interventional studies to verify hypotheses and define tools that can be applied in the general population. Epidemiological and preclinical studies will continue to provide new information on risk/protective factors and pathological mechanisms. The international collaboration among research teams involved in ongoing multidomain RCTs will allow the sharing of experiences and discussions on methodological aspects of these studies. This can help in interpretation of results, identification and solution of problems related to intervention strategies, and refinement of preventative approaches.

Since a cure for dementia is not yet available, finding effective preventive strategies is essential for a sustainable society in an aging world. As dementia, cardiovascular diseases, stroke, and diabetes mellitus - all major public health problems - share several risk factors, public health efforts promoting a healthier lifestyle have the potential to enhance health status in advanced age.

\section{Abbreviations}

AD, Alzheimer's disease; AHRQ, Agency for Healthcare Research and Quality; ApoE, apolipoprotein E; BMI, body mass index; CAIDE, Cardiovascular Risk Factors, Aging and Incidence of Dementia; EDPI, European Dementia Prevention Initiative; FINGER, Finnish Geriatric Intervention Study to Prevent Cognitive Impairment and Disability; HRT, hormone replacement therapy; MAPT, Multidomain Alzheimer Preventive Trial; NIH, National Institutes of

Health; NSAID, non-steroidal anti-inflammatory drug; PreDIVA, Prevention of Dementia by Intensive Vascular Care; PUFA, polyunsaturated fatty acid; RCT, randomized controlled trial; $V a D$, vascular dementia.

Competing interests

The authors declare that they have no competing interests. 


\section{Acknowledgments}

This study was supported by Karolinska Institutet (Sweden), the Swedish Research Council for Medical Research, the Academy of Finland, the La Carita Foundation of Finland, the Alzheimer's Association (USA), and the Swedish Foundations of Ragnhild och Einar Lundströms-Minne-Lindhés, StohnesStiftelse, and Gamla-Tjänarinnor. The funding sources did not play any role in the design or conduct of the study or in the collection, management, analysis, or interpretation of data or in the preparation, review, or approval of the manuscript. Editor Kimberly Kane revised the language in the manuscript.

\section{Author details}

'Aging Research Center, Department of Neurobiology, Care Sciences and Society (NVS), Karolinska Institutet (KI)-Stockholm University, Gävlegatan 16 (9th floor) SE-113 30, Stockholm, Sweden. ${ }^{2}$ Institute of Gerontology and Geriatrics, Department of Clinical and Experimental Medicine, University of Perugia, S. Andrea delle Fratte 06156 Perugia, Italy. ${ }^{3}$ Department of Neurology, University of Eastern Finland, Yliopistonranta 1B, P.O. Box 1627, FIN 70211 Kuopio, Finland

\section{Published: 13 February 2012}

\section{References}

1. Schneider JA, Arvanitakis Z, Bang W, Bennett DA: Mixed brain pathologies account for most dementia cases in community-dwelling older persons. Neurology 2007, 69:2197-2204.

2. Viswanathan A, Rocca WA, Tzourio C: Vascular risk factors and dementia: how to move forward? Neurology 2009, 72:368-374.

3. Fratiglioni L, Launer LJ, Andersen K, Breteler MM, Copeland JR, Dartigues JF, Lobo A, Martinez-Lage J, Soininen H, Hofman A: Incidence of dementia and major subtypes in Europe: a collaborative study of population-based cohorts. Neurologic Diseases in the Elderly Research Group. Neurology 2000, 54:S10-15.

4. Alzheimer's Disease International: World Alzheimer Report 2010. The Global Economic Impact of Dementia. London: Alzheimer's Disease International; 2010 [http://www.alz.co.uk/research/files/

WorldAlzheimerReport2010ExecutiveSummary.pdf]

5. Qiu C, Kivipelto M, von Strauss E: Epidemiology of Alzheimer's disease: occurrence, determinants, and strategies toward intervention. Dialogues Clin Neurosci 2009, 11:111-128.

6. Qiu C, Fratiglioni L: Epidemiology of the dementias. In Dementia History and Incidence. Volume I. Edited by McNamara P. Santa Barbara, CA: ABC-CLIO Press, Inc.; 2011

7. Fratiglioni L, Qiu C: Prevention of cognitive decline in ageing: dementia as the target, delayed onset as the goal. Lancet Neurol 2011, 10:778-779.

8. Kivipelto $M$, Solomon A: Preventive neurology: on the way from knowledge to action. Neurology 2009, 73:168-169.

9. Williams JW, Plassman BL, Burke J, Holsinger T, Benjamin S: Preventing Alzheimer's Disease and Cognitive Decline. Evidence Report/Technology Assessment No. 193. (Prepared by the Duke Evidence-based Practice Center under Contract No. HHSA 290-2007-10066-I). Rockville, MD: Agency for Healthcare Research and Quality: AHRQ Publication No. 10-E005; 2010.

10. National Institutes of Health: Consensus Development Conference Statement on Preventing Alzheimer's Disease and Cognitive Decline. Bethesda, MD: National Institutes of Health; 2010

11. Hughes TF, Ganguli M: Modifiable midlife risk factors for late-life cognitive impairment and dementia. Curr Psychiatry Rev 2009, 5:73-92

12. Flicker $L$, Liu-Ambrose T, Kramer AF: Why so negative about preventing cognitive decline and dementia? The jury has already come to the verdict for physical activity and smoking cessation. Br J Sports Med 2010, 45:465-467

13. Qiu C, Kivipelto M, Fratiglioni L: Preventing Alzheimer disease and cognitive decline. Ann Intern Med 2011, 154:211; author reply 212-213.

14. Qiu C, Winblad B, Fratiglioni L: The age-dependent relation of blood pressure to cognitive function and dementia. Lancet Neurol 2005 , 4:487-499.

15. Qiu C, Xu W, Fratiglioni L: Vascular and psychosocial factors in Alzheimer's disease: epidemiological evidence toward intervention. J Alzheimers Dis 2010, 20:689-697.

16. Kivipelto M, Helkala EL, Laakso MP, Hanninen T, Hallikainen M, Alhainen K, livonen S, Mannermaa A, Tuomilehto J, Nissinen A, Soininen H: Apolipoprotein E epsilon4 allele, elevated midlife total cholesterol level, and high midlife systolic blood pressure are independent risk factors for late-life Alzheimer disease. Ann Intern Med 2002, 137:149-155.

17. Mielke MM, Zandi PP, Sjogren M, Gustafson D, Ostling S, Steen B, Skoog I: High total cholesterol levels in late life associated with a reduced risk of dementia. Neurology 2005, 64:1689-1695.

18. Atti AR, Palmer K, Volpato S, Winblad B, De Ronchi D, Fratiglioni L: Late-life body mass index and dementia incidence: nine-year follow-up data from the Kungsholmen Project. J Am Geriatr Soc 2008, 56:111-116.

19. Kivipelto M, Ngandu T, Fratiglioni L, Viitanen M, Kareholt I, Winblad B, Helkala EL, Tuomilehto J, Soininen H, Nissinen A: Obesity and vascular risk factors at midlife and the risk of dementia and Alzheimer disease. Arch Neurol 2005, 62:1556-1560

20. Xu W, Qiu C, Gatz M, Pedersen NL, Johansson B, Fratiglioni L: Mid- and latelife diabetes in relation to the risk of dementia: a population-based twin study. Diabetes 2009, 58:71-77.

21. Barnes DE, Yaffe $K$ : The projected effect of risk factor reduction on Alzheimer's disease prevalence. Lancet Neurol 2011, 10:819-828.

22. Ownby RL, Crocco E, Acevedo A, John V, Loewenstein D: Depression and risk for Alzheimer disease: systematic review, meta-analysis, and metaregression analysis. Arch Gen Psychiatry 2006, 63:530-538.

23. Karp A, Andel R, Parker MG, Wang HX, Winblad B, Fratiglioni L: Mentally stimulating activities at work during midlife and dementia risk after age 75: follow-up study from the Kungsholmen Project. Am J Geriatr Psychiatry 2009, 17:227-236

24. Rovio S, Kareholt I, Helkala EL, Viitanen M, Winblad B, Tuomilehto J, Soininen $\mathrm{H}$, Nissinen A, Kivipelto M: Leisure-time physical activity at midlife and the risk of dementia and Alzheimer's disease. Lancet Neuro/ 2005, 4:705-711.

25. Hakansson K, Rovio S, Helkala EL, Vilska AR, Winblad B, Soininen H, Nissinen A Mohammed AH, Kivipelto M: Association between mid-life marital status and cognitive function in later life: population based cohort study. BMJ 2009, 339:b2462.

26. Paillard-Borg S, Fratiglioni L, Winblad B, Wang HX: Leisure activities in late life in relation to dementia risk: principal component analysis. Dement Geriatr Cogn Disord 2009, 28:136-144.

27. Barberger-Gateau P, Raffaitin C, Letenneur L, Berr C, Tzourio C, Dartigues JF, Alperovitch A: Dietary patterns and risk of dementia: the Three-City cohort study. Neurology 2007, 69:1921-1930.

28. Morris MC, Evans DA, Bienias JL, Tangney CC, Bennett DA, Aggarwal N, Schneider J, Wilson RS: Dietary fats and the risk of incident Alzheimer disease. Arch Neurol 2003, 60:194-200.

29. Devore EE, Grodstein F, van Rooij FJ, Hofman A, Stampfer MJ, Witteman JC, Breteler MM: Dietary antioxidants and long-term risk of dementia. Arch Neurol 2010, 67:819-825.

30. Morris MC, Evans DA, Tangney CC, Bienias JL, Wilson RS, Aggarwal NT, Scherr PA: Relation of the tocopherol forms to incident Alzheimer disease and to cognitive change. Am J Clin Nutr 2005, 81:508-514.

31. Scarmeas N, Stern $Y$, Tang MX, Mayeux R, Luchsinger JA: Mediterranean diet and risk for Alzheimer's disease. Ann Neuro/ 2006, 59:912-921.

32. Kivipelto M, Ngandu T, Laatikainen T, Winblad B, Soininen H, Tuomilehto J: Risk score for the prediction of dementia risk in 20 years among middle aged people: a longitudinal, population-based study. Lancet Neuro/ 2006, 5:735-741.

33. Qiu C, Xu W, Winblad B, Fratiglioni L: Vascular risk profiles for dementia and Alzheimer's disease in very old people: a population-based longitudinal study. J Alzheimers Dis 2010, 20:293-300.

34. Barnes DE, Covinsky KE, Whitmer RA, Kuller LH, Lopez OL, Yaffe K: Predicting risk of dementia in older adults: The late-life dementia risk index. Neurology 2009, 73:173-179.

35. Barnes DE, Covinsky KE, Whitmer RA, Kuller LH, Lopez OL, Yaffe K: Commentary on 'Developing a national strategy to prevent dementia: Leon Thal Symposium 2009.' Dementia risk indices: a framework for identifying individuals with a high dementia risk. Alzheimers Dement 2010, 6:138-141.

36. Kivipelto M, Rovio S, Ngandu T, Kareholt I, Eskelinen M, Winblad B, Hachinski V, Cedazo-Minguez A, Soininen H, Tuomilehto J, Nissinen A: Apolipoprotein E epsilon4 magnifies lifestyle risks for dementia: a population-based study. J Cell Mol Med 2008, 12:2762-2771.

37. Wang HX, Gustafson D, Kivipelto M, Pedersen NL, Skoog I, Winblad B, Fratiglioni L: Education halves the risk of dementia due to apolipoprotein $\varepsilon 4$ allele: a collaborative study from the Swedish Brain Power initiative Neurobiol Aging 2011 Nov 4. [Epub ahead of print]. 
38. Daviglus ML, Bell CC, Berrettini W, Bowen PE, Connolly ES Jr., Cox NJ, Dunbar Jacob JM, Granieri EC, Hunt G, McGarry K, Patel D, Potosky AL, Sanders-Bush E, Silberberg D, Trevisan M: National Institutes of Health State-of-theScience Conference statement: preventing alzheimer disease and cognitive decline. Ann Intern Med 2011, 153:176-181.

39. Solomon A, Kivipelto M: Cholesterol-modifying strategies for Alzheimer's disease. Expert Rev Neurother 2009, 9:695-709.

40. Malouf R, Grimley Evans J: Folic acid with or without vitamin B12 for the prevention and treatment of healthy elderly and demented people. Cochrane Database Syst Rev 2008, (4):CD004514.

41. Wald DS, Kasturiratne A, Simmonds M: Effect of folic acid, with or without other B vitamins, on cognitive decline: meta-analysis of randomized trials. Am J Med 2010, 123:522-527.e2.

42. Komulainen P, Kivipelto M, Lakka TA, Savonen K, Hassinen M, Kiviniemi V, Hanninen T, Rauramaa R: Exercise, fitness and cognition - A randomised controlled trial in older individuals: The DR's EXTRA study. European Geriatric Medicine 2010, 1:266-272.

43. Rocca WA, Grossardt BR, Shuster LT: Oophorectomy, menopause, estrogen treatment, and cognitive aging: clinical evidence for a window of opportunity. Brain Res 2011, 1379:188-198.

44. Whitmer RA, Quesenberry CP, Zhou J, Yaffe K: Timing of hormone therapy and dementia: the critical window theory revisited. Ann Neurol 2011, 69:163-169.

45. Isaac MG, Quinn R, Tabet N: Vitamin E for Alzheimer's disease and mild cognitive impairment. Cochrane Database Syst Rev 2008, (3):CD002854.

46. Mangialasche F, Kivipelto M, Mecocci P, Rizzuto D, Palmer K, Winblad B, Fratiglioni L: High plasma levels of vitamin $E$ forms and reduced Alzheimer's disease risk in advanced age. J Alzheimers Dis 2010, 20:1029-1037.

47. Schurks M, Glynn RJ, Rist PM, Tzourio C, Kurth T: Effects of vitamin E on stroke subtypes: meta-analysis of randomised controlled trials. BMJ 2010 341:c5702.

48. Andrieu S, Aboderin I, Baeyens JP, Beard J, Benetos A, Berrut G, Brainin M, Cha HB, Chen LK, Du P, Forette B, Forette F, Franco A, Fratiglioni L, GilletteGuyonnet S, Gold G, Gomez F, Guimaraes R, Gustafson D, Khachaturian A, Luchsinger J, Mangialasche F, Mathiex-Fortunet H, Michel JP, Richard E,Schneider LS, Solomon A, Vellas B: IAGG Workshop: Health Promotion Program on Prevention of Late Onset Dementia. J Nutr Health Aging 2011, 15:562-575.
49. Richard E, Van den Heuvel E, Moll van Charante EP, Achthoven L, Vermeulen $\mathrm{M}$, Bindels PJ, Van Gool WA: Prevention of dementia by intensive vascular care (PreDIVA): a cluster-randomized trial in progress. Alzheimer Dis Assoc Disord 2009, 23:198-204.

50. Gillette-Guyonnet S, Andrieu S, Dantoine T, Dartigues JF, Touchon J, Vellas B: Commentary on 'A roadmap for the prevention of dementia II. Leon Thal Symposium 2008.'The Multidomain Alzheimer Preventive Trial (MAPT): a new approach to the prevention of Alzheimer's disease. Alzheimers Dement 2009, 5:114-121.

51. Kivipelto M, Mangialasche F, Solomon A, Mecocci P, Winblad B: Future of clinical trials. In International Psychogeriatric Association (IPA) 15th International Congress. 6-9 September 2011. The Hague, The Netherlands: IPA Bulletin in press; 2011

52. Sonnen JA, Santa Cruz K, Hemmy LS, Woltjer R, Leverenz JB, Montine KS, Jack CR, Kaye J, Lim K, Larson EB, White L, Montine TJ: Ecology of the aging human brain. Arch Neurol 2011, 68:1049-1056.

53. West SG, Duan N, Pequegnat W, Gaist P, Des Jarlais DC, Holtgrave D, Szapocznik J, Fishbein M, Rapkin B, Clatts M, Mullen PD: Alternatives to the randomized controlled trial. Am J Public Health 2008, 98:1359-1366

54. Zhu L, Fratiglioni L, Guo Z, Basun H, Corder EH, Winblad B, Viitanen M: Incidence of dementia in relation to stroke and the apolipoprotein $\mathrm{E}$ epsilon 4 allele in the very old. Findings from a population-based longitudinal study. Stroke 2000, 31:53-60.

55. Honig LS, Tang MX, Albert S, Costa R, Luchsinger J, Manly J, Stern Y, Mayeux R: Stroke and the risk of Alzheimer disease. Arch Neurol 2003, 60:1707-1712

56. Bushnell CD, Zimmer LO, Pan W, Olson DM, Zhao X, Meteleva T, Schwamm L, Ovbiagele B, Williams L, Labresh KA, Peterson ED: Persistence with stroke prevention medications 3 months after hospitalization. Arch Neurol 2010, 67:1456-1463.

57. Qiu C, Winblad B, Marengoni A, Klarin I, Fastbom J, Fratiglioni L: Heart failure and risk of dementia and Alzheimer disease: a population-based cohort study. Arch Intern Med 2006, 166:1003-1008.

doi:10.1186/alzrt104

Cite this article as: Mangialasche F, et al.: Dementia prevention: current epidemiological evidence and future perspective. Alzheimer's Research \& Therapy 2012, 4:6. 